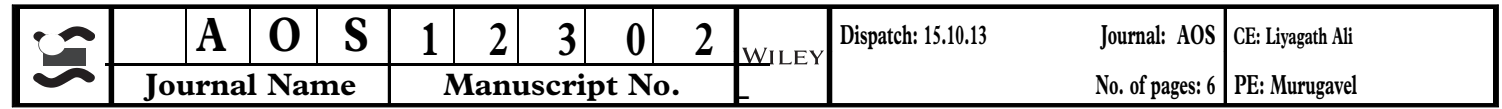

\title{
Visual performance and ocular abnormalities in deaf children and young adults: a literature review
}

\author{
Richard Hollingsworth, ${ }^{1}$ Amanda K. Ludlow, ${ }^{2}$ Arnold Wilkins, ${ }^{3}$ \\ Richard Calver ${ }^{1}$ and Peter M. Allen ${ }^{1}$ \\ ${ }^{1}$ Vision and Eye Research Unit, Department of Vision and Hearing Sciences, Anglia \\ Ruskin University, Cambridge, UK \\ ${ }^{2}$ Department of Psychology, University of Birmingham, Edgbaston, UK \\ $1{ }^{3}$ Department of Psychology, University of Essex, Essex, UK
}

\begin{abstract}
.
Visual defects are common in deaf individuals. Refractive error and ocular motor abnormalities are frequently reported, with hyperopia, myopia, astigmatism and anomalies of binocular vision, all showing a greater prevalence in deaf individuals compared with the general population. Near visual function in deaf individuals has been relatively neglected in the literature to date. Comparisons between studies are problematic due to differences in methodology and population characteristics. Any untreated visual defect has the potential to impair the development of language, with consequences for education more generally, and there is a need to improve screening and treatments of deaf children.
\end{abstract}

Key words: binocular vision - deaf - reading - refraction - vision

Acta Ophthalmol.

(C) 2013 Acta Ophthalmologica Scandinavica Foundation. Published by John Wiley \& Sons Ltd

doi: $10.1111 /$ aos. 12302

\section{Overview}

Deaf people are thought to view the visual world very differently from people with normal hearing, due to adaptation to their hearing loss and consequential changes to their communication strategy. For example, deaf people who use sign language must be able to discriminate quickly between facial expressions in order to interpret signed sentences. In a large study of hearing-impaired students, over a quarter were found to have visual defects, the majority of which were untreated, the most common being refractive error (Gogate et al. 2009). Therefore, assessment and treatment of visual defects, especially refractive errors and binocular vision anomalies, are essential to allow the best possible social and professional adjustment for deaf individuals. In this study, we review the literature concerned with visual function in deaf children and young adults aged 1-21 and suggest areas where further research is desirable. We will use visual defects to refer to those conditions usually detected in optometric practice and ocular abnormalities to refer to conditions usually detected in hospital ophthalmology clinics.
The review process involved a comprehensive electronic literature search from various data bases: OneFile, Health Reference Center Academic, Social Sciences Citation Index (Web of Science), SciVerse ScienceDirect (Elsevier), Science Citation Index Expanded (Web of Science), Medline (NLM), MLA International Bibliography, American Psychological Association (APA), Project MUSE, ERIC (US Department of Education), Oxford Journals (Oxford University Press), SpringerLink, SAGE Journals, Wiley Online Library, PMC (PubMed Central), Nature.com (Nature Publishing Group) and Google Scholar. The following key words and combinations of words were used: deaf children vision, vision and deafness, deaf vision, eye and deafness, ophthalmic and deaf, optometry and deaf, refraction and deaf, vision and hearing, ophthalmological and deaf, ophthalmological and hearing, vision and ear, deaf and blind, eye and deaf, deaf vision and reading, reading and deaf, vision reading and deaf, near vision and deaf, near vision and hearing impaired.

\section{Introduction}

In the UK, there are approximately 1 per 1000 children born each year with hearing impairment defined as a hear- 
ing loss in the better ear of more than $40 \mathrm{~dB}$ averaged over $0.5,1,2$ and $4 \mathrm{kHz}$ (Fortnum et al. 2001). The British Society of Audiology (2004) classifies hearing levels as shown in Table 1.

Visual defects and ocular abnormalities have consistently been documented as being more prevalent in deaf individuals (Table 2) than comparative groups of hearing individuals (Pollard \& Neumaier 1974).

Refractive error is common in deaf individuals including children with uncomplicated deafness (i.e. no evidence of family history, congenital or deafness caused by infective or metabolic disease) even allowing for emmetropization. There is little consensus as to whether refractive errors are more frequent in the congenitally deaf than in those who acquire deafness at a later stage of life (e.g. Guy et al. 2003)

Ophthalmological screening regimes have been implemented for deaf children in an attempt to maximize visual abilities and minimize social and educational disadvantages (Siatkowski et al. 1993; Guy et al. 2003; Hanioglu-Kargi et al. 2003). Despite the awareness that visual abilities are essential in a non-hearing world, it would seem that very little attention has previously been given to near visual function, and in particular reading. Perfetti \& Sandak (2000) suggest that the use of phonology (the study of how sounds are organized and used in languages) is associated with higher levels of reading skills among deaf readers and that 'the effectiveness of the visual channel is not an issue'. On the other hand, Martin et al. (2012) suggested that deaf children who have reduced dynamic visual acuities may also have reduced vestibular responses and reading difficulties. Children with congenital vestibular abnormalities displayed gross motor developmental problems that the authors suggested may impede the usual ocular motor/ vestibular relationship. This in turn could impact on visual stability and hence acquisition of reading (Martin et al. 2012).
Due to the difficulty in recruiting deaf participants, several studies have found themselves reliant on retrospective examination of medical data (Table 2). This methodology reduces the validity of the data (Woodruff 1986) and is reliant on observations gathered from many different sources, giving results that are at best hypothesis generating (Hess 2004).

There are few studies that include direct comparisons between deaf groups and a matched hearing control group (Pollard \& Neumaier 1974). Instead, the majority of studies have chosen to compare their data with previous studies on a hearing population (Regenbogen \& Godel 1985; Leguire et al. 1992; Guy et al. 2003; Hanioglu-Kargi et al. 2003). The majority of studies have reported simply age range and gender. However, some studies have divided gender and ages into year groupings (Pollard \& Neumaier 1974; Mohindra 1976). One study, conducted in Washington DC, USA (Suchman 1967), specified racial grouping without attributing deafness or visual dysfunction to this factor. The racial grouping may or may not be

Table 1. The British Society of Audiology (2011) classified hearing levels.

Mild hearing loss $\quad 20-40(\mathrm{~dB})$ Able to hear and repeat words spoken in normal voice at 1 mimportant, but the majority of studies Moderate hearing loss 41-70 (dB) Able to hear and repeat words spoken in raised voice at $1 \mathrm{~m}$ have not directly addressed this issue Severe hearing loss $\quad 71-95(\mathrm{~dB})$ Able to hear some words when shouted into better ear Profound hearing loss $>95(\mathrm{~dB}) \quad$ Unable to hear and understand even a shouted voice and have been ethnically biased to the country of origin (Table 2).

Table 2. Percentage of deaf individuals with visual defects or ocular abnormalities in 21 studies.

\begin{tabular}{|c|c|c|c|c|c|c|c|}
\hline Studies & $\begin{array}{l}\text { No of } \\
\text { subjects } N\end{array}$ & Male & Female & $\begin{array}{l}\text { Age range } \\
\text { Years }\end{array}$ & $\begin{array}{l}\text { Visual defects/Ocular } \\
\text { Abnormalities \% }\end{array}$ & $\begin{array}{l}\text { Data collection } \\
\text { institution }\end{array}$ & $\begin{array}{l}\text { County of } \\
\text { origin }\end{array}$ \\
\hline Braly 1938 & 422 & $*$ & $*$ & $*$ & 38 & Deaf School & USA \\
\hline Stockwell 1952 & 960 & 555 & 405 & $2-20$ & 46 & Deaf School & USA \\
\hline Suchman 1967 & 104 & 51 & 53 & $4-12$ & 58 & Deaf School & USA \\
\hline Alexander 1973 & 572 & $*$ & $*$ & $5-20$ & 50 & Deaf School & Canada \\
\hline Pollard \& Neumaier 1974 & 511 & 303 & 208 & $5-20$ & 33 & Deaf School & USA \\
\hline Mohindra 1976 & 77 & 33 & 42 & $5-17$ & 75 & Deaf School & USA \\
\hline Regenbogen \& Godel 1985 & 150 & 92 & 58 & $1-14$ & 45 & HEC & Israel \\
\hline Woodruff 1986 & 460 & $*$ & $*$ & $*$ & 55 & Deaf School $^{\dagger}$ & Canada \\
\hline Leguire et al. 1992 & 505 & $*$ & $*$ & $6-22$ & 49 & HEC & USA \\
\hline Siatkowski et al. 1993 & 54 & 28 & 26 & $2-14$ & 61 & $\mathrm{HEC}$ & USA \\
\hline Armitage et al. 1995 & 83 & 41 & 42 & $1.3-16$ & 35 & $\mathrm{HAC}$ & UK \\
\hline Brinks et al. 2001 & 231 & $*$ & $*$ & $10-21$ & 48 & Deaf School & USA \\
\hline Mafong et al. 2002 & 114 & 60 & 54 & $1-18$ & 31 & $\mathrm{HES}^{\dagger}$ & USA \\
\hline Hanioglu-Kargi et al. 2003 & 104 & 68 & 36 & $7-20$ & 40 & Deaf School & Turkey \\
\hline Guy et al. 2003 & 122 & 61 & 61 & $0.7-16.8$ & 43 & $\mathrm{CDC}$ & UK \\
\hline Khandekar et al. 2009 & 223 & 142 & 81 & $5-15$ & 19 & Deaf School & Oman \\
\hline Bakhshaee et al. 2009 & 50 & 19 & 31 & $*-7$ & 32 & Deaf School & Iran \\
\hline Sharma et al. 2009 & 226 & 112 & 114 & $*-18$ & 22 & $\mathrm{HEC}^{\dagger}$ & USA \\
\hline Gogate et al. 2009 & 901 & 554 & 347 & $4-21$ & 24 & Deaf School & India \\
\hline Bist et al. 2011 & 279 & 154 & 125 & $5-20$ & 28 & Deaf School & Nepal \\
\hline Abah et al. 2011 & 608 & 373 & 235 & $5-38$ & 21 & Deaf School & Nigeria \\
\hline
\end{tabular}

* No data available. HEC, Hospital eye clinic. HAC, Hospital audiology clinic. CDC, Child development centre.

$\uparrow$ Retrospective study. 


\section{Visual defects - refractive and binocular vision abnormalities}

Refractive and binocular vision abnormalities have typically been the most commonly reported. The prevalence of hyperopia, myopia and astigmatism is between $18 \%$ and $39 \%$ (Pollard \& Neumaier 1974; Mohindra 1976; Regenbogen \& Godel 1985; Guy et al. 2003; Gogate et al. 2009) and binocular vision abnormalities (e.g. strabismus) between $5.3 \%$ and $18 \%$ (Regenbogen \& Godel 1985; Hanio-

11 glu-Kargi et al. 2003).

Various methodologies and classification criteria have been used in the assessment of vision/visual acuity (Table 3). Bist et al. (2011), for example, assessed vision and visual acuity with a Snellen tumbling ' $E$ ' test chart, which do not require literacy. Whilst most research has used traditional Snellen charts at $6 \mathrm{~m}$, there has been little use of $\log$ MAR assessment despite it being acknowledged as a superior measurement (Lovie-Kitchin 2008). Visual acuity of young children has been assessed with a variety of tests including Sheridan Gardiner cards, Kay pictures, Lea Crowded Symbols (near vision) and for preverbal children, Cardiff preferential looking cards (Armitage et al. 1995; Guy et al. 2003). Crowded Kay pictures and Lea pictures are considered the most appropriate tests for young children with the
LogMAR crowded acuity test and the Sonsken Log MAR chart being the tests of choice for children over 3 years (Saunders 2010). The reliance on Snellen acuity charts as compared to the Log MAR system may be at least in part due to the location and the clinical nature of the majority of studies where Snellen charts are more commonly available.

Near vision assessments in deaf individuals are a rarity within the literature and when they have been undertaken, the reduced Snellen tumbling ' $E$ ' letter charts have typically been used (Regenbogen \& Godel 1985). For example, Hanioglu-Kargi et al. (2003) assessed with a Snellen reduced E near chart and Khandekar et al. (2009) with near Lea symbols. Although measurement of near vision was undertaken by Khandekar et al. (2009), no near vision results were presented. It is evident that many of the deaf studies from developing countries (Gogate et al. 2009; Khandekar et al. 2009; Abah et al. 2011) have greater reliance on non-reading 'illiterate' tests possibly indicating the greater difficulties these children have in acquiring basic reading skills when compared with their hearing counterparts or simply that the levels of literacy are much lower in these countries.

Refractive error has often been assessed objectively using retinoscopy both with, (Mohindra 1976; Regenbogen \& Godel 1985; Leguire et al. 1992; Siatkowski et al. 1993) and without cycloplegia. Evidence of subjective non-cycloplegic refractions having been performed is limited. Cyloplegic refractions are the most accurate method of assessing refraction for children because of the control of accommodative effort (Fotouhi et al. 2012). Inclusion criteria for refractive errors have considerable variation. For example, Guy et al. (2003) set inclusion for spherical ametropia at $\geq 4.00 \mathrm{D}$ (dioptres) whilst Armitage et al (1995) included hyperopia of $\geq 1.50 \mathrm{D}$ with esotropia ( $\geq 3.00 \mathrm{D}$ without esotropia). Outlined below are a few of the most commonly observed refractive and binocular vision abnormalities as documented in deaf individuals.

\section{Hyperopia}

Hyperopic ametropia associated with deafness is the most commonly reported refractive error (Alexander 1973; Mohindra 1976; Regenbogen \& Godel 1985; Siatkowski et al. 1993; Armitage et al. 1995; Abah et al. 2011) with the prevalence varying between $8 \%$ ( $\geq 2.25$ D; Pollard \& Neumaier 1974 non-cycloplegic refraction) and $31.5 \%$ $(\geq 2.50$ D; Siatkowski et al. 1993 ; cycloplegic refraction) as compared to between 4\% ( $\geq 2.00 \mathrm{D}$; Fan et al. 2004) and $12.8 \%(\geq 1.25 \mathrm{D}$; Kleinstein et al. $2003)$ in a normal hearing population for cycloplegic refractions and $7.7 \%$ ( $\geq 1.50 \mathrm{D}$; Junghans et al. 2002) for non-cycloplegic refractions.

Table 3. Selection of deaf studies showing variation in criteria used to classify visual defects

\begin{tabular}{|c|c|c|c|c|c|c|c|c|}
\hline Studies & $\begin{array}{l}\text { Number of } \\
\text { participants }\end{array}$ & & $\begin{array}{l}\text { Hyperopia } \\
\text { (D) }\end{array}$ & $\begin{array}{l}\text { Myopia } \\
\text { (D) }\end{array}$ & $\begin{array}{l}\text { Astigmatism } \\
\text { (D) }\end{array}$ & Anisometropia & Amblyopia & $\begin{array}{l}\text { Near } \\
\text { vision }\end{array}$ \\
\hline \multirow{2}{*}{$\begin{array}{l}\text { Pollard \& } \\
\text { Neumaier } \\
1974\end{array}$} & \multirow[t]{2}{*}{511} & Criterion & $>2.25$ & $>0.75$ & $>1.25$ & $>1.25$ & $\leq 6 / 12(20 / 40)$ & * \\
\hline & & Number or $(\%)$ defect & $41(8)$ & $68(13.3)$ & $30(5.9)$ & $30(5.9)$ & $9(1.8)$ & $*$ \\
\hline \multirow{2}{*}{$\begin{array}{l}\text { Leguire } \\
\text { et al. } 1992\end{array}$} & \multirow[t]{2}{*}{505} & Criterion & $\geq 3.00$ & $>1.00$ & $\geq 1.00$ & $\geq 1.00$ & $<6 / 9(20 / 30)$ & * \\
\hline & & Number or $(\%)$ defect & $24(4.8)$ & $39(7.7)$ & $56(11.1)$ & $37(7.3)$ & $22(4.4)$ & * \\
\hline \multirow{2}{*}{$\begin{array}{l}\text { Siatkowski } \\
\text { et al. } 1993\end{array}$} & \multirow[t]{2}{*}{54} & Criterion & $>2.50$ & $>1.00$ & $>1.50$ & $>1.00$ & * & $*$ \\
\hline & & Number or $(\%)$ defect & $25(31.5)$ & $4(7.4)$ & $2(3.7)$ & $1(1.8)$ & * & * \\
\hline \multirow{2}{*}{$\begin{array}{l}\text { Armitage } \\
\text { et al. } 1995\end{array}$} & \multirow[t]{2}{*}{83} & Criterion & $\geq 3.00^{\ddagger}\left(\geq 1.50^{\dagger}\right)$ & $\geq 1.00$ & $>1.50$ & $>1.00$ & $*$ & $*$ \\
\hline & & Number or $(\%)$ defect & $12(14.4)$ & $12(14.4)$ & $11(13.2)$ & $4(4.8)$ & * & * \\
\hline \multirow[t]{2}{*}{ Guy et al. 2003} & \multirow[t]{2}{*}{110} & Criterion & $\geq 4.00$ & $\geq 4.00$ & $>1.50$ & $>1.00$ & $*$ & * \\
\hline & & Number $(\%)$ defect & $11(10)$ & $23(21)$ & $8(7.3)$ & $1(0.91)$ & $4(3.6)$ & $*$ \\
\hline \multirow{2}{*}{$\begin{array}{l}\text { Hanioglu-Kargi } \\
\text { et al. } 2003\end{array}$} & \multirow[t]{2}{*}{104} & Criterion & $\geq 1.50$ & $>1.00$ & $\geq 1.50$ & $\geq 2.00$ & $<6 / 9(20 / 30)$ & * \\
\hline & & Number or $(\%)$ defect & $10(9.6)$ & $6(5.8)$ & $15(14.4)$ & $\overline{5}(4.8)$ & $16(15.3)$ & $*$ \\
\hline \multirow{2}{*}{$\begin{array}{l}\text { Gogate } \\
\text { et al. } 2009\end{array}$} & \multirow[t]{2}{*}{901} & Criterion & $\geq 1.00$ & $\geq 0.50$ & $\geq 0.50$ & $*$ & $<6 / 60(20 / 200)$ & $*$ \\
\hline & & Number or $(\%)$ defect & $41(4.5)$ & $113(12.5)$ & $13(1.4)$ & * & $3(0.3)$ & * \\
\hline \multirow{2}{*}{$\begin{array}{l}\text { Khandekar } \\
\text { et al. } 2009\end{array}$} & \multirow[t]{2}{*}{223} & Criterion & * & $*$ & * & * & $*$ & $*$ \\
\hline & & Number or $(\%)$ defect & * & * & * & * & * & $15(6.5)$ \\
\hline
\end{tabular}

\footnotetext{
* No data available.

$\dagger$ With esotropia.

$\ddagger$ Without esotropia. D, dioptres.
} 


\section{Myopia}

Myopia is the second most frequently reported visual defect. There is a greater prevalence of myopia in deaf and hearing-impaired individuals (Leguire et al. 1992) even when allowing for the increase in myopia with age (Coleman 1970; Saw et al. 2005). Estimates of the prevalence of myopia in the deaf have ranged from $6 \%$ (>1.00 D; Hanioglu-Kargi et al. 2003) to $20.9 \%$ (>4.00 D; Guy et al. 2003).

\section{Astigmatism}

There appears to be a greater prevalence of astigmatism in the deaf and hearing impaired, with Pollard \& Neumaier (1974) reporting $7.3 \%$ in their deaf participants compared with $1.4 \%$ in their group of hearing children. Compared with other visual defects, studies have shown far greater agreement with criteria for astigmatism, ranging from $\geq 1.00 \mathrm{D}$ to $\geq 1.50 \mathrm{D}$ (Pollard \& Neumaier 1974; Siatkowski et al. 1993; Armitage et al. 1995; Guy et al. 2003),

15 although Hanioglu-Kargi et al. (2003) used $\mathrm{a} \geq 2.00 \mathrm{D}$ criterion and reported prevalence in the deaf of $14.4 \%$. Woodruff (1986) in his retrospective study suggested that higher levels of astigmatism $(>1.00 \mathrm{D})$ may be associated with congenital rubella, although no associations with disease process or level of deafness have been suggested elsewhere. Mohindra (1976) subdivided her astigmatic participants into 'with-the-rule' (steeper corneal curvature vertically) and 'against-the-rule' (steeper curvature horizontally). Corneal curvature was measured using keratometry, and there were twice the number of 'with-the-rule' astigmats than 'against-the-rule', although no relationship to deafness was described. A higher prevalence of with-the-rule astigmatism is in accordance with studies in a normal population (Khabazkhoob et al. 2010). Woodruff (1986) also reviewed corneal curvature suggesting congenital rubella subjects show greater curvature and a high prevalence of microphthalmia.

\section{Amblyopia}

A greater prevalence of amblyopia has consistently been shown in the deaf, with criteria ranging from $<6 / 9(20 / 30)$ (Hanioglu-Kargi et al. 2003) to $<6 / 60$ (20/200) (Gogate et al. 2009) and prev- alence ranging between $4.4 \%$ (Leguire et al. 1992) and $14.4 \%$ (Hanioglu-Kargi et al. 2003). The increased occurrence of amblyopia has variously been attributed to ocular pathology, strabismus, cataracts and anisometropia.

\section{Anisometropia}

Anisometropia also has an increased prevalence in the deaf. Definitions of anisometropia have been extremely variable. For example, Pollard \& Neumaier (1974) set a criterion of $1.25 \mathrm{D}$ difference between eyes whilst HaniogluKargi et al. (2003) used $\geq 2.00 \mathrm{D}$ and Regenbogen \& Godel (1985) $\geq 3.00$ D.

\section{Binocular vision abnormalities}

Strabismus (heterotropia) and heterophoria have commonly been measured with a simple cover/uncover test (Suchman 1967; Guy et al. 2003). Heterophoria has occasionally been quantified using an alternating cover test in association with a prism bar, although few studies have reported the magnitude of phoria. Alexander (1973) used a cover/ uncover prism test and Maddox rod to quantify the heterophoria. Whilst these tests were stated in the methods, only strabismic anomalies were published in the results. Alexander found $11 \%$ of 572 deaf children with strabismus, 16 children having accommodative esotropia with a further 29 being non-accommodative. Mohindra (1976) used the cover test for distance and near, reporting results for the distance cover test only for a prevalence of 9\% strabismus and $10 \%$ heterophoria. Deviations of $>10$ prism dioptres have been considered significant (Leguire et al. 1992; Hanioglu-Kargi et al. 2003) and have been reported as more common in deaf cohorts compared with normal hearing cohorts. Regenbogen \& Godel (1985) found a prevalence of $4.6 \%$ compared with $1.8 \%$ in a normal hearing population whilst Pollard \& Neumaier (1974) found no difference with strabismus in $4.9 \%$ of their deaf participants compared with $4.8 \%$ in a hearing group, although the criteria in their hearing group was 'less rigid'. Accommodation and associated phoria (fixation disparity) have not featured in the reviewed papers. These assessments would give a greater insight into the co-ordination of the eyes, which is especially important with near vision.

\section{Stereopsis}

Stereopsis has been measured in early studies using the wings of a toy butterfly and more recently with the Titmus stereo fly, Wirt dot (Mohindra 1976) and TNO tests (Hanioglu-Kargi et al. 2003). Normal stereo acuity has been set at $\leq 100$ seconds of arc for the majority of studies. Mohindra (1976), using the stereo fly and Wirt dot tests, found over $32 \%$ of the deaf participants with a stereopsis of $>100$ seconds of arc. Reduced stereopsis is associated with refractive error and/or an oculomotor abnormality that is in accordance with the greater prevalence of strabismus (Alexander 1973) and amblyopia (Hanioglu-Kargi et al. 2003) in deaf children.

\section{Contrast sensitivity (CS)}

Ushers syndrome is associated with deafness and retinitis pigmentosa, and in the only study to have assessed contrast sensitivity, a deficit was shown (Hartong et al. 2006).

\section{Colour vision}

Colour vision has been assessed with the Ishihara Colour Test (Mohindra 1976; Regenbogen \& Godel 1985), D15 16 Test (Khandekar et al. 2009) and Farnsworth-Munsell 100-Hue Test (Mohindra 1976). Mohindra (1976) found $2.1 \%$ of females $(N=43)$ and $6.9 \%$ of males $(N=29)$ to have colour defects using Ishihara and Farnsworth 100-Hue tests. These levels are consistent with larger scale normative studies and would suggest little variation in the prevalence of colour defects in the deaf (Birch \& Platts 1993).

As the research outlined above clearly shows, the prevalence of hyperopia, myopia, astigmatism and binocular anomalies is increased in deaf individuals, irrespective of whether the deafness is congenital or acquired, severe or mild.

\section{Range and severity of hearing impairment and visual performance}

Early studies qualitatively grouped deafness into broad levels of moderate, severe and profound (Suchman 1967), whilst later studies have attempted a quantitative assessment of hearing loss. 
For example, Armitage et al. (1995) assessed 83 children; 46 of them having severe hearing loss $(>70 \mathrm{~dB})$ and 37 having profound hearing loss ( $>90 \mathrm{~dB})$. They assessed hearing with audiograms and hearing thresholds with octave frequencies of 500, 1000, 2000 and $4000 \mathrm{~Hz}$. They found 15 of the severe hearing loss group and 14 of the profound hearing loss group (total $35 \%$ ) met their criteria for having a visual defect (see Table 2). Stockwell (1952) assessed refractive status in acquired and congenital deaf individuals, finding marginally higher levels of ocular defects in the congenitally deaf group, although $13 \%$ of the total cohort had an unknown cause of deafness.

Leguire et al. (1992), categorized subjects into mild hearing loss (30$45 \mathrm{~dB})$, moderate loss (45-60 dB) and severe loss (60-80 dB) with these being grouped together as hearing impaired, whilst profound loss $(>80 \mathrm{~dB})$ was categorized as individuals being deaf. Visual defects and ocular abnormalities were found in all categories to be more prevalent than in normative data, although the prevalence of refractive defects was similar in the hearingimpaired and the deaf groups (hearing impaired $21.6 \%$, deaf $24.54 \%$ ). Similarly, Khandekar et al. (2009) investigated visual defects in the profoundly deaf $>81 \mathrm{~dB}$ and severely deaf 61$80 \mathrm{~dB}$, but did not find any association between visual acuity and contrast sensitivity defects and level of hearing impairment. There was a notable association between increased ocular anomalies and rubella. Armitage et al. (1995) compared ocular defects between congenital and acquired deafness, finding no significant differences between these groups.

In summary, no strong relationship between level of deafness and visual defects has been found (Leguire et al. 1992), with few studies quantifying the level of hearing loss. Whilst the classification criteria differ between studies, these have been dependent on the application of international hearing standards or the use of national standards. Although refractive and binocular vision abnormalities are clearly more prevalent in deaf children when compared to people with normal hearing, there may only be a weak association between the defects and the level of deafness.

\section{Ocular abnormalities}

The retina and the cochlea structures are formed at the same developmental stage and embryonic layer, so any pathological defect within these areas could lead to oculo-auditory defects (Armitage et al. 1995; Nikolopoulos et al. 2006). There is little consensus in the literature regarding which diseases should be considered for inclusion in deaf vision studies with generic terms such as 'hereditary' and 'acquired' conditions being the most commonly reported. Some early studies such as that by Suchman (1967) have examined the external eye and observed the red reflex of the fundus giving little information of posterior segment pathology. Other studies (e.g. Guy et al. 2003) assessed pathological abnormalities in greater detail, having categorized the pathologies into genetic syndromal, autosomal recessive, autosomal dominant, infective, metabolic, acquired and unknown causes. Sixtythree of the 122 children in the study by Guy et al. (2003) had a genetic cause of their deafness, 13 were linked to known oculoauditory syndromes such as Usher's syndrome, Leigh's encephalopathy and Wildervanck's syndrome, and 45 had an unknown cause. This greater detail has given better insight into the associations between deafness, vision and the disease processes, enabling better identification of individuals who may be at risk from these disease processes, whether genetic or acquired, and allowing treatment at an earlier stage of development. In comparison, Regenbogen \& Godel (1985) grouped the pathological conditions into broader areas: fundus, macular, external, pigmentary retinal changes, retinitis pigmentosa and optic disc atrophy but without relating the findings to any specific syndrome.

A diverse range of diseases has been related to deafness and vision defects, and many of these diseases are very rare. Woodruff (1986) reviewed the case histories of 420 children attending schools for the deaf in Ontario, reported congenital rubella as the most significant pathology and highlighted its association with an increased prevalence of strabismus and amblyopia, secondary to retinopathy and cataracts. Other studies have also found ocular pathologies associated with rubella (Mohindra 1976; Leguire et al.
1992; Mitchell et al. 2001). Fortunately, congenital rubella is now a relatively infrequent cause of deafness particularly within developed countries (Nikolopoulos et al. 2006). Consequently, it is now more common to attribute deafness and visual problems to genetic causes and the more prevalent infective problems, for example cytomegalovirus, toxoplasmosis and syphilis (Guy et al. 2003; Nikolopoulos et al. 2006). Unfortunately, 'unknown aetiology' is by far the largest pathological category in much of the research. Nikolopoulos et al. (2006) 17 reviewed in detail the ophthalmological abnormalities associated with deafness, and readers are referred to this paper for a full review.

In conclusion, it is now well established that associations between deafness, ocular pathology and visual performance exist. Assessment of deaf children's vision should always consider ocular abnormalities, together with the refractive and binocular status.

\section{Communication and near vision}

Visual defects in the deaf are particularly important due to the social and educational ramifications of having a dual disability (Dammeyer 2010). The possible effects of visual defects on communication skills have not been adequately researched, although it has been well established that deaf children have difficulties in reading and lag behind their hearing peers (Musselman 2000; Perfetti \& Sandak 2000; GoldinMeadow \& Mayberry 2001). This developmental delay has often been attributed to a lack of phonic awareness of the words, making comprehension problematic. Surprisingly, there has been relatively little assessment of the levels of near vision function and binocular co-ordination in these children: visual defects appear to have simply not been considered relevant. Indeed, there are a variety of proposed methods in the literature for reading acquisition in deaf children with a large proportion dedicated to phonic defects. Less attention has been given to logographic and orthographic (visual) routes to reading (Booth et al. 2000; Perfetti \& Sandak 2000). Whilst phonic understanding of words would appear 
essential for reading, visual recognition of the words is the starting point for any reading task. Therefore, any functional near visual impairment may impede this development.

\section{Conclusion}

Research over the past 70 years has established a strong relationship between deafness and ocular abnormalities. Most studies have (almost) exclusively investigated distance vision and have shown higher levels of dysfunction in the deaf when compared with normal hearing groups. Near vision is especially important when considering the altruistic objective of enhancing social and educational abilities but has received little study even though it is essential for the acquisition of knowledge via sign language, lip reading, facial gestures, reading text, figures or pictorially.

\section{References}

Abah E, Oladigbolu K, Samaila E, Merali H, Ahmed A \& Abubakar T (2011): Ophthalmologic abnormalities among deaf students in Kaduna, Northern Nigeria. Ann Afr Med 10: 29-33.

Alexander JC (1973): Ocular abnormalities among congenitally deaf children. Can J Ophthalmol 8: 428-433.

Armitage I, Burke J \& Buffin J (1995): Visual impairment in severe and profound sensorineural deafness. Br Med J 73: 53-56.

Bakhshaee M, Banaee T, Ghasemi MM, Nourizadeh N, Shojaee B, Shahriari S \& Tayarani HR (2009): Ophthalmic disturbances in children with sensorineural hearing loss. Eur Arch Otorhinolaryngol 266: 823-825.

Birch J \& Platts C (1993): Colour vision screening in children: an evaluation of three pseudoisochromatic tests. Ophthalmic Physiol Opt 13: 344-349.

Bist J, Adhikari P \& Sharma A (2011): Ocular morbidity in hearing impaired schoolchildren. Child Care Health Dev 37: 394-397.

Booth JR, Perfetti CA, Macwhinney B \& Hunt SB (2000): The association of rapid temporal perception with orthographic and phonological processing in children and adults with reading impairment. Sci Stud Read 4: 101132.

Braly K (1938): A study of defective vision among deaf children. Am Ann Deaf 83: 192.

British Society of Audiology (2004): Pure-tone air and bone conduction threshold audiometry with and without masking and determination of uncomfortable loudness levels. ???

18 British Society of Audiology.

Coleman HM (1970): An analysis of the visual status of an entire school population. J Am Optom Assoc 41: 341-347.
Dammeyer J (2010): Psychosocial development in a Danish population of children with cochlear implants and deaf and hard-of-hearing children. J Deaf Stud Deaf Educ 15: 50-58.

Fan DSP, Lam DSC, Lam RF, Lau JTF, Chong KS, Cheung EYY, Lia RYK \& Chew SJ (2004): Prevalence, incidence and progression of myopia of school children in Hong Kong. Invest Ophthalmol Vis Sci 45: 1071-1075.

Fortnum HM, Summerfield AQ, Marshall DH, Davis AC, Bamford JM, Davis A, Yoshinagaitano C \& Hind S (2001): Prevalence of permanent childhood hearing impairment in the United Kingdom and implications for universal neonatal hearing screening: questionnaire based ascertainment study Commentary: universal newborn hearing screening: implications for coordinating and developing services for deaf and hearing impaired children. Br Med J 323: 536.

Fotouhi A, Morgan IG, Iribarren R, Khabazkhoob M \& Hashemi H (2012): Validity of noncycloplegic refraction in the assessment of refractive errors: the Tehran Eye Study. Acta Ophthalmol 90: 380-386.

Gogate P, Rishikeshi N, Mehata R, Ranade S, Kharat J \& Deshpande M (2009): Visual impairment in the hearing impaired students. Indian J Ophthalmol 57: 451-453.

Goldin-Meadow S \& Mayberry RI (2001): How do profoundly deaf children learn to read? Learning Disabilities Research \& Practice 16: 222-229.

Guy R, Nicholson J, Pannu SS \& Holden R (2003): A clinical evaluation of ophthalmic assessment in children with sensori-neural deafness. Child Care Health Dev 29: 377-84.

Hanioglu-Kargi S, Koksal M, Tomac S, Ugurba SH \& Alpay A (2003): Ophthalmologic abnormalities in children from a Turkish school for the deaf. Turk J Pediatr 45: 39-42.

Hartong DT, Berson EL \& Dryja TP (2006): Retinitis pigmentosa. Lancet 368: 1795-1809.

Hess DR (2004): Retrospective studies and chart reviews. Res Care 49: 1171-1174.

Junghans B, Keily PM, Crewther DP \& Crewther SG (2002): Referral rates for a functional vision screening among a large cosmopolitan sample of Australian children. Ophthalmic Physiol Opt 22: 10-25.

Khabazkhoob M, Hashemi H, Yazdani K, Mehravaran S, Yekta A \& Fotouhi A (2010): Keratometry measurements, corneal astigmatism and irregularity in a normal population: the Tehran Eye Study. Ophthalmic Physiol Opt 30: 800-805.

Khandekar R, Al FM, Al JB, Al HS \& Abdulamgeed T (2009): Visual function and ocular status of children with hearing impairment in Oman: a case series. Indian $\mathbf{J}$ Ophthalmol 57: 228-229.

Kleinstein RN, Jones LA, Hullet S et al. (2003): Refractive error and ethnicity on children. Arch Ophthalmol 121: 1141-1147.

Leguire L, Fillman R, Fishman D, Bremer D \& Rogers G (1992): A prospective study of ocular abnormalities in hearing impaired and deaf students. Ear Nose Throat J 71: 643-646.

Lovie-Kitchin JE (2008): Validity and reliability of visual acuity measurements. Ophthalmic Physiol Opt 8: 363-370.
Mafong DD, Pletcher SD, Hoyt C \& Lalwani AK (2002): Ocular findings in children with congenital sensorineural hearing loss. Arch Otolaryngol Head Neck Surg 128: 1303.

Martin W, Jelsma J \& Rogers C (2012): Motor proficiency and dynamic visual acuity in children with bilateral sensorineural hearing loss. Int J Pediatr Otorhinolaryngol 70: 1957 1965.

Mitchell VB, William HM, Cardwell M, Otos M \& Richard GW (2001): Ophthalmologic screening of deaf students in Oregon. J Pediatr Ophthalmol Strabismus 38: 11-15.

Mohindra I (1976): Vision profile of deaf children. Am J Optom Physiol Opt 53: 412-419.

Musselman C (2000): How do children who can't hear learn to read an alphabetic script? A review of the literature on reading and deafness J Deaf Stud Deaf Educ 5: 9-31.

Nikolopoulos T, LIoumi D, Stamataki S, O DG \& Guest M (2006): Evidence-based overview of ophthalmic disorders in deaf children: a literature update. Otol Neurotol 27: 1-24.

Perfetti CA \& Sandak R (2000): Reading optimally builds on spoken language. J Deaf Stud Deaf Educ, 5: 32-50.

Pollard G \& Neumaier R (1974): Vision characteristics of deaf students. Am Ann Deaf 119: $740-745$.

Regenbogen L \& Godel V (1985): Ocular deficiencies in deaf children. J Pediatr Ophthalmol Strabismus 22: 231-233.

Saunders KJ (2010): Testing visual acuity of young children: an evidence-based guide for optometrists. Optom Pract 11: 161-168.

Saw SM, Tong L, Chua WH, Chia KS, Koh D, Tan DTH \& Katz J (2005): Incidence and progression of myopia in Singaporean school children. Invest Ophthalmol Vis Sci 46: 51-57.

Sharma A, Ruscetta MN \& Chi DH (2009): Ophthalmologic findings in children with sensorineural hearing loss. Arch Otolaryngol Head Neck Surg 135: 119-123.

Siatkowski R, Flynn J, Hodges A \& Balkany T (1993): Visual function in children with congenital sensorineural deafness. Trans Am Ophthalmol Soc 91: 309-318.

Stockwell E (1952): Visual defects in the deaf child. AMA Arch Ophthalmol 48: 428-432.

Suchman RG (1967): Visual impairment among deaf children: frequency and educational consequences. Arch Ophthalmol 77: 18-21.

Woodruff M (1986): Differential effects of various causes of deafness on the eyes, refractive errors, and vision of children. Am J Optom Physiol Opt 63: 668-675.

Received on October 23rd, 2012.

Accepted on September 19th, 2013.

\section{Correspondence:}

Dr Peter M. Allen

Vision and Eye Research Unit

Department of Vision and Hearing Sciences

Anglia Ruskin University

Cambridge CB1 1PT

UK

Tel: + ????

Fax: + ????

Email: peter.allen@anglia.ac.uk 


\section{Author Query Form}

Journal: $\quad$ AOS

Article: $\quad 12302$

Dear Author,

During the copy-editing of your paper, the following queries arose. Please respond to these by marking up your proofs with the necessary changes/additions. Please write your answers on the query sheet if there is insufficient space on the page proofs. Please write clearly and follow the conventions shown on the attached corrections sheet. If returning the proof by fax do not write too close to the paper's edge. Please remember that illegible mark-ups may delay publication. Many thanks for your assistance.

\begin{tabular}{|c|c|c|}
\hline Query reference & Query & Remark \\
\hline 1 & AUTHOR: Please check that authors and their affiliations are correct. & \\
\hline 2 & $\begin{array}{l}\text { AUTHOR: Please check and provide telephone and fax number for corresponding } \\
\text { author. }\end{array}$ & \\
\hline 3 & AUTHOR: Please check the level headings. & \\
\hline 4 & $\begin{array}{l}\text { AUTHOR: Suchmaan } 1967 \text { has been changed to Suchman } 1967 \text { so that this } \\
\text { citation matches the Reference List. Please confirm that this is correct. }\end{array}$ & \\
\hline 5 & $\begin{array}{l}\text { AUTHOR: Alexander et al. } 1973 \text { has been changed to Alexander } 1973 \text { so that this } \\
\text { citation matches the Reference List. Please confirm that this is correct. }\end{array}$ & \\
\hline 6 & $\begin{array}{l}\text { AUTHOR: Pollard et al. } 1974 \text { has been changed to Pollard and Neumaier } 1974 \text { so } \\
\text { that this citation matches the Reference List. Please confirm that this is correct. }\end{array}$ & \\
\hline 7 & $\begin{array}{l}\text { AUTHOR: Regenbogen } 1985 \text { has been changed to Regenbogen and Godel } 1985 \text { so } \\
\text { that this citation matches the Reference List. Please confirm that this is correct. }\end{array}$ & \\
\hline 8 & $\begin{array}{l}\text { AUTHOR: Siatkowski et al. } 1994 \text { has been changed to Siatkowski et al. } 1993 \text { so } \\
\text { that this citation matches the Reference List. Please confirm that this is correct. }\end{array}$ & \\
\hline 9 & $\begin{array}{l}\text { AUTHOR: Brinks et al. } 2001 \text { has not been included in the Reference List, please } \\
\text { supply full publication details. }\end{array}$ & \\
\hline 10 & $\begin{array}{l}\text { AUTHOR: Bist et al. } 2010 \text { has been changed to Bist et al. } 2011 \text { so that this } \\
\text { citation matches the Reference List. Please confirm that this is correct. }\end{array}$ & \\
\hline 11 & $\begin{array}{l}\text { AUTHOR: Regenbogem \& Golden } 1985 \text { has been changed to Regenbogen and } \\
\text { Godel } 1985 \text { so that this citation matches the Reference List. Please confirm that } \\
\text { this is correct. }\end{array}$ & \\
\hline 12 & $\begin{array}{l}\text { AUTHOR: Pollard et al., } 1974 \text { has been changed to Pollard and Neumaier } 1974 \text { so } \\
\text { that this citation matches the Reference List. Please confirm that this is correct. }\end{array}$ & \\
\hline 13 & $\begin{array}{l}\text { AUTHOR: Siatowski et al., } 1994 \text { has been changed to Siatkowski et al. } 1993 \text { so } \\
\text { that this citation matches the Reference List. Please confirm that this is correct. }\end{array}$ & \\
\hline 14 & $\begin{array}{l}\text { AUTHOR: Khadehar et al. (2009) has been changed to Khandekar et al. (2009) so } \\
\text { that this citation matches the Reference List. Please confirm that this is correct. }\end{array}$ & \\
\hline 15 & $\begin{array}{l}\text { AUTHOR: Hanioglu-Karg et al. (2003) has been changed to Hanioglu-Kargi } \\
\text { et al. (2003) so that this citation matches the Reference List. Please confirm that } \\
\text { this is correct. }\end{array}$ & \\
\hline 16 & $\begin{array}{l}\text { AUTHOR: Regenbogen \& Godel 1974; has been changed to Regenbogen and } \\
\text { Godel } 1985 \text { so that this citation matches the Reference List. Please confirm that } \\
\text { this is correct. }\end{array}$ & \\
\hline 17 & $\begin{array}{l}\text { AUTHOR: Nikololpoulos et al., (2006) has been changed to Nikolopoulos et al. } \\
\text { (2006) so that this citation matches the Reference List. Please confirm that this is } \\
\text { correct. }\end{array}$ & \\
\hline
\end{tabular}


Required software to e-Annotate PDFs: Adobe Acrobat Professional or Adobe Reader (version 8.0 or above). (Note that this document uses screenshots from Adobe Reader $\mathrm{X}$ )

The latest version of Acrobat Reader can be downloaded for free at:http://get.adobe.com/reader/

Once you have Acrobat Reader open on your computer, click on the Comment tab at the right of the toolbar:

닙

This will open up a panel down the right side of the document. The majority of tools you will use for annotating your proof will be in the Annotations section, pictured opposite. We've picked out some of these tools below:

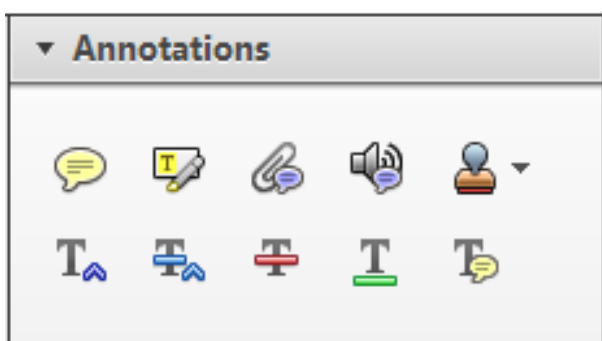

1. Replace (Ins) Tool - for replacing text.

\section{Strikes a line through text and opens up a text} box where replacement text can be entered.

\section{How to use it}

- Highlight a word or sentence.

- Click on the Replace (Ins) icon in the Annotations section.

- Type the replacement text into the blue box that appears.

Idard tramework for the analysis of $\mathrm{m}$ icy Nevertheless, it also led to exog،

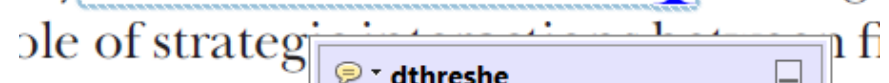
aber of comp 08/06/2011 15:58:17 $\quad$ o

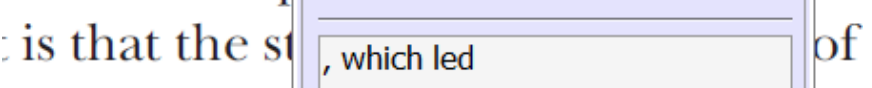
nain compo: be level, are exc nc

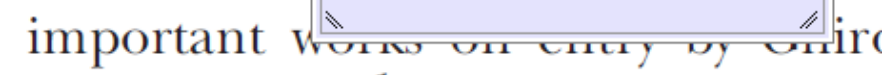
M heneforth) ${ }^{1}$ we anen the 'hlarl $\mathrm{h}$

3. Add note to text Tool - for highlighting a section to be changed to bold or italic.

Th Highlights text in yellow and opens up a text box where comments can be entered.

\section{How to use it}

- Highlight the relevant section of text.

- Click on the Add note to text icon in the Annotations section.

- Type instruction on what should be changed regarding the text into the yellow box that annears.

namic responses of mark ups ent with the VAR evidence

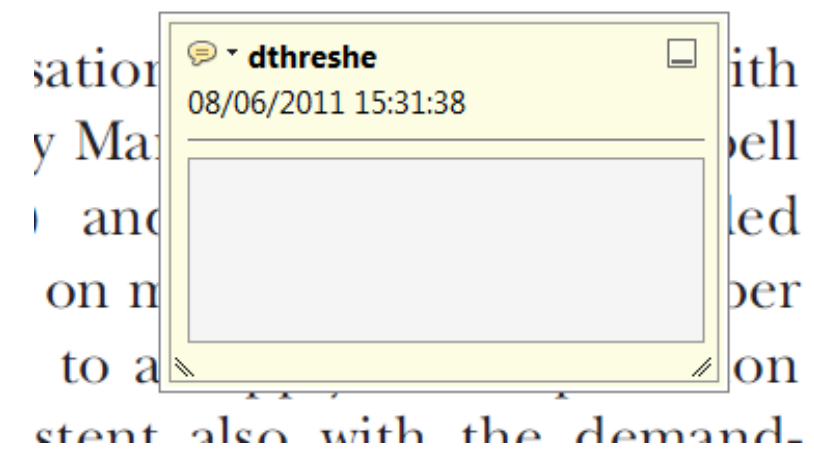

2. Strikethrough (Del) Tool - for deleting text.

Thikes a red line through text that is to be deleted.

\section{How to use it}

- Highlight a word or sentence.

- Click on the Strikethrough (Del) icon in the Annotations section.

there is no room for extra protits al c ups are zero and the number of ret) values are not determined by Blanchard and Kiyetaki (1987), rfect competition in general equilil ts of aggregate demand and supply lassical framework assuming monol eon an evorenois number of firms

\section{Add sticky note Tool - for making notes at} specific points in the text.

\section{Marks a point in the proof where a comment} needs to be highlighted.

\section{How to use it}

- Click on the Add sticky note icon in the Annotations section.

- Click at the point in the proof where the comment should be inserted.

- Type the comment into the yellow box that appears.

lallu allu suppiy silucks. Iviusl ul

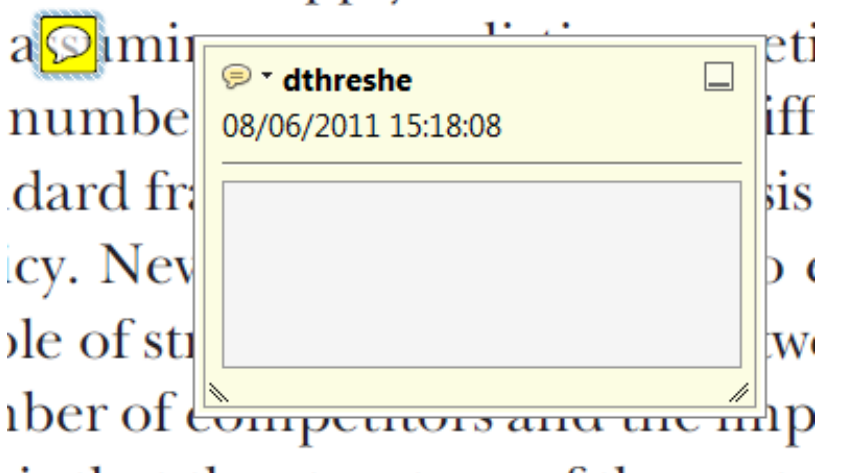

is that the structure of the secto 
5. Attach File Tool - for inserting large amounts of text or replacement figures.

Inserts an icon linking to the attached file in the appropriate pace in the text.

How to use it

- Click on the Attach File icon in the Annotations section.

- Click on the proof to where you'd like the attached file to be linked.

- Select the file to be attached from your computer or network.

- Select the colour and type of icon that will appear in the proof. Click OK.

E N D

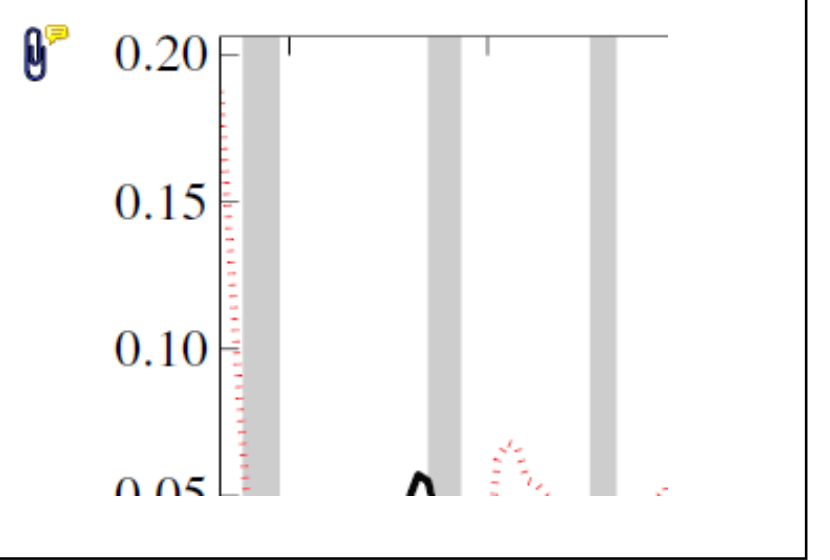

6. Add stamp Tool - for approving a proof if no corrections are required.

- Inserts a selected stamp onto an appropriate place in the proof

\section{How to use it}

- $\quad$ Click on the Add stamp icon in the Annotations section.

- Select the stamp you want to use. (The Approved stamp is usually available directly in the menu that appears).

- Click on the proof where you'd like the stamp to appear. (Where a proof is to be approved as it is, this would normally be on the first page).

of the Dusiness cycie, starting with the on perfect competition, constant ret

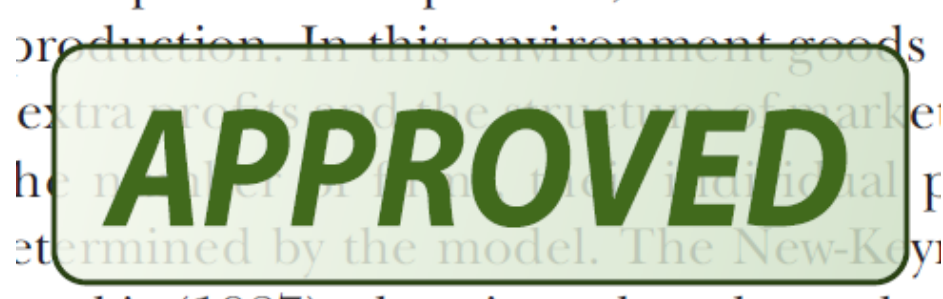

otaki (1987), has introduced produc general equilibrium models with nomin
- Drawing Markups

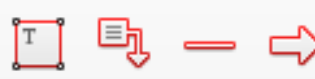

$0 \square \sqrt{6} D$

\section{How to use it}

- Click on one of the shapes in the Drawing Markups section.

- Click on the proof at the relevant point and draw the selected shape with the cursor.

- To add a comment to the drawn shape, move the cursor over the shape until an arrowhead appears.

- Double click on the shape and type any text in the red box that appears.
7. Drawing Markups Tools - for drawing shapes, lines and freeform annotations on proofs and commenting on these marks.

Allows shapes, lines and freeform annotations to be drawn on proofs and for comment to be made on these marks..

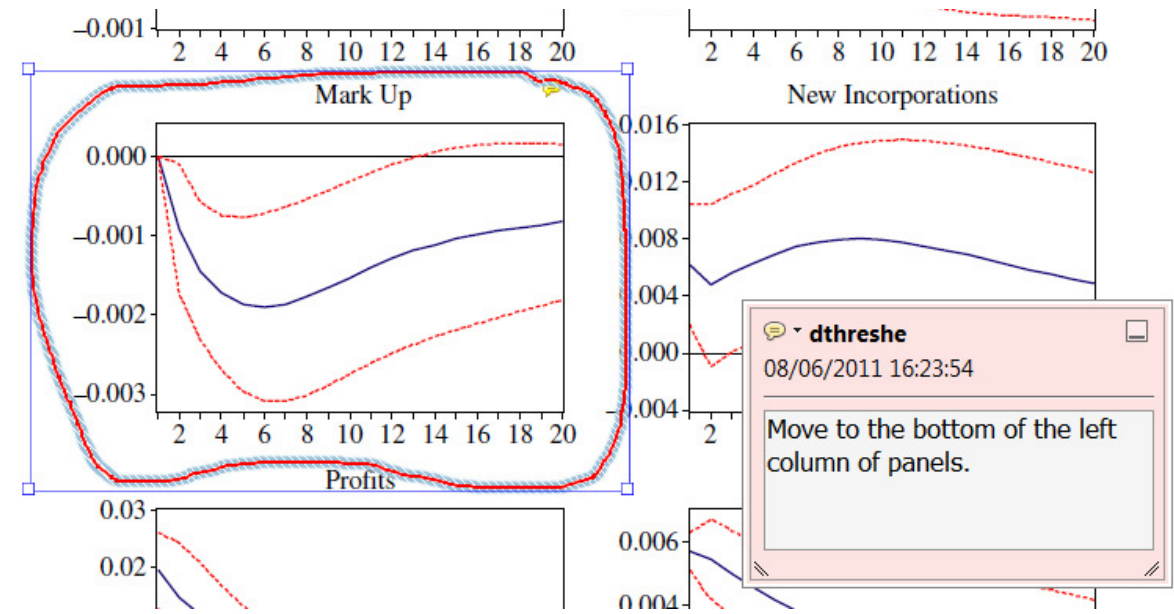

For further information on how to annotate proofs, click on the Help menu to reveal a list of further options:

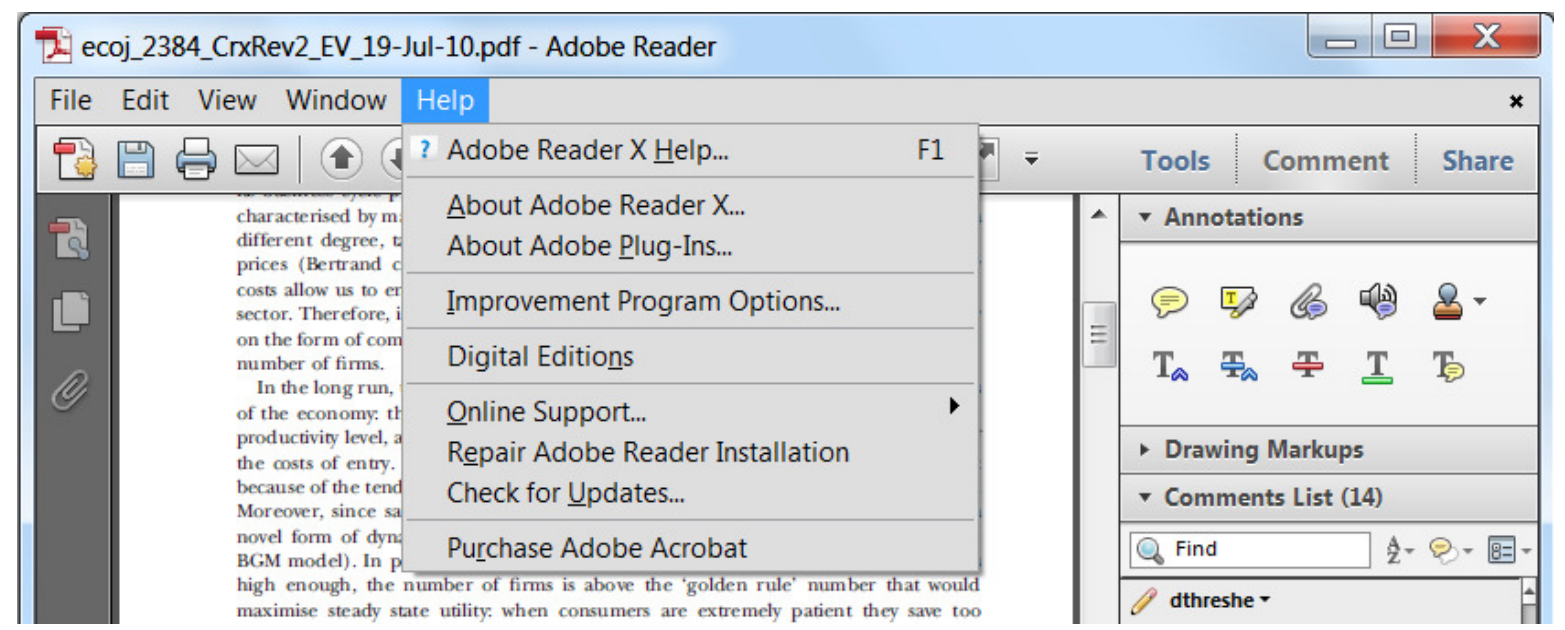

